$\xi=-1$

\title{
Application of scenario-driven hazard analysis in the solid rocket booster
}

\author{
Kouroush Jenab $^{1 *}$, Nikita Ottosen ${ }^{2}$, Saeid Moslehpour ${ }^{3}$ \\ ${ }^{1}$ Faculty of College of Aeronautics Embry-Riddle Aeronautical University 600 S. Clyde Morris Blvd. Daytona Beach, FL 32114-3900, USA \\ ${ }^{2}$ Assistant Campus Director - Crestview Embry-Riddle Aeronautical University 5210B S. Ferdon Blvd. Crestview, FL 32536-9269, USA \\ ${ }^{3}$ Faculty of College of Engineering Hartford University 200 Bloomfield Avenue, West Hartford, CT 06117, USA \\ *Corresponding author E-mail: kouroush.jenab@erau.edu
}

\begin{abstract}
Bibliographical Notes: Kouroush Jenab is a senior member of IEEE, received the B.Sc. degree from the IE Department at Isfahan University of Technology (1989), the M.Sc. degree from the IE Department at Tehran Polytechnic (1992), and the Ph.D. degree from the Department of Mechanical Engineering at the University of Ottawa (2005). He served as a senior engineer/manager in auto, and hightech industries for 18 years. He joined the National Research Council Canada as a research officer where he participated in several international research projects. In 2006, he joined the Department of Mechanical and Industrial Engineering at Ryerson University, Toronto as assistant professor. Currently, Dr. Jenab is Faculty of the College of Aeronautics at Embry-riddle Aeronautical University, FL, USA. He has published over 110 papers in international scientific journals based on his experiences in industries.

Nikita Ottosen is a current Systems Engineering graduate student at Embry-Riddle Aeronautical University. She received her undergraduate degree from ERAU in Aeronautics and is currently working as an Assistant Campus Director at the Crestview, FL campus. She gained valuable knowledge previously working for the Boeing Company and Seattle-Tacoma International Airport, known as The Port of Seattle, in Seattle, Washington. During her time at The Port of Seattle she worked alongside the Wildlife Management department to conduct a study on effective wildlife management strategies. Her study will become a part of a future Airport Cooperative Research Program (ACRP) publication, sponsored by the FAA's Transportation Research Board of the National Academies.

Saeid Moslehpour is a full professor and department chair in the Electrical and Computer Engineering Department in the College of Engineering, Technology, and Architecture at the University of Hartford. He holds Ph.D. (1993) from Iowa State University and Bachelor of Science (1989) and Master of Science (1990) degrees from University of Central Missouri. His research interests include failure analysis, logic design, CPLDs, FPGAs, Embedded electronic system testing and distance learning.
\end{abstract}

Keywords: Solid Rocket Booster; Field Joint; Scenario-Driven Hazard Analysis.

\section{Introduction}

The solid rocket booster field joint was developed to allow segments of the solid rocket booster (SRB) to be connected together. Sections are made of the SRB to include fuel sections, nozzle and nose cap. See Figure 1.

The intersections of each part are connected together by a field joint. Prior to the Challenger design, these field joints were held together by 77 pins which were made from steel. The design configuration of the field joints were clevis and tang. Clevis and tang contains three alignment slots and the steel pins ensure correct alignment of each segment. Once the segments are connected with the pins, a seal is placed over the joint. This is a synthetic rubber O-ring which was developed to seal out any combustion products. Layered putty was used to keep high temperatures from starting combustion of the fuel cells. The SRB were designed this way to help prevent from having any problems.

However, problems still existed with the Solid Rocket Booster, specifically the field joint. The design was insufficient for the external factors faced by the SRB. Structural analysis was performed on the critical structural elements. This was focused on areas where anomalies had been noted. An anomaly is something that stands out from the normal, expected result. Anomalies are used frequently in quality assurance to predict defects in the system process. Areas where anomalies were looked at closely and the following was found:

a.) Ring area connected to the external tank was noted to have stress along the fasteners.

b.) Aft skirt structural tests pointed out an anomaly in the critical weld of the skirt.

Anomalies are not the only way to prevent system risks during the development process. The cause of the challenger accident was not related to an anomaly found in the design; it was due to corrosion of the O-ring located in the field joint. This led to leakage of combustible gasses which ignited during the mission. Risk assessment techniques can be utilized during development processes to help predict and avoid catastrophic failures such as this. In this study, authors discuss risk assessments and how they are effective in quality assurance. 


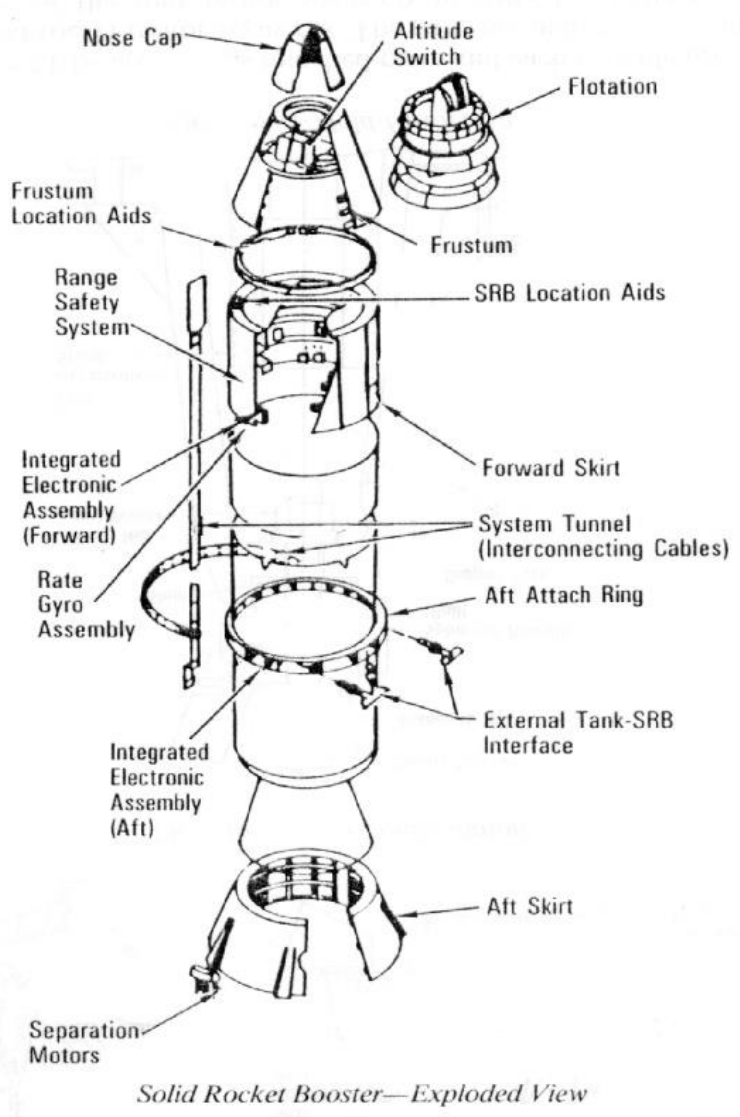

Fig. 1: Segments of SRB [1].

\section{Literature review}

Risk assessment strategies are vastly spreading throughout multiple industries. As processes become complex and large, it is hard to identify defects in the development of a product. The National Aeronautics and Space Administration (NASA) would have benefited from the use of a risk assessment strategy during the development of the Challenger, specifically the Solid Rocket Booster [2], [3], [4], and [21].

As Main [20] simply states in his discussion on personal safety; "The goal of risk assessment is to reduce risks to an acceptable (or tolerable) level." With the development of the SRB, many risks were over looked. John F. Kennedy Space Center [18] discusses the reuse of the hardware to keep costs lowered. This imposes many risks related to fatigue of materials. Leone [19] states that the SRB used for the challenger was the largest solid rocket booster ever developed that will be used for flight. As the development of the SRB progressed, pushing many risk factors, utilizing a proper assessment strategy could have prevented future defects.

Leone [19] talked about the political pressures of the development of the SRB. Although not a technical aspect of the design process, these external stresses can break down a development process. Leone [19] mentioned that there was completion deadlines enforced and the industry began questioning the design affordability. Suggestions of competition of the manufacturing contract would help with affordability and quality. This is not always the case and valuable evidence was never known pertaining to competition and faster development.

Szondy [22] talks about the assembly process being cautiously done. "Six Sigma is a management methodology which allows companies to use data to eliminate defects in any process" [5]. The goal of achieving Six Sigma is that a process must not product a defect. Szondy [22] goes on to discuss cutting down on process steps during the assembly. Forty-seven steps which included moving parts of the SRB were cut down to 7. Bos illustrates in the drawing of the segments that there are many moving parts [1]. By cutting out nearly 40 steps to move these parts cut down a lot of risk factors. Recently, SRB failure analysis has been extensively studied by using Monte Carlo simulation [7, 10], Hazard Platform [11], fuzzy FMEA [12], Failure analysis [13], Cause-consequence analysis [14], FMEA [15], Bayesian method [16], Critical safety analysis [17]

There are many risks that NASA encountered during the development of the solid rocket booster. This study shows that by implementing a risk assessment process, such as scenario-driven hazard analysis (SDHA), these risks could be decreased. SDHA would help to analysis the associated risk NASA faced during the system development process.

\section{Solid rocket booster analysis using scenario- driven hazard analysis}

Scenario-driven hazard analysis was developed to allow a complete process to thoroughly analyze system synergistic risks [8]. Understanding the undercurrents of accidents is mandatory for the process to work. Accidents are harmful and unplanned. A disruption of the expected sequence of events happens, thus resulting in an accident. There are three main categories that need to be identified for SDHA to proceed. These categories are initiators, subsequent contributors and the primary hazard.

Scenario-driven hazard analysis is considered the inverse of accident investigation. If SDHA is done perfectly, accident investigation would not exist. However, nothing is $100 \%$ in Quality Assurance, it is only a sought-after goal within systems engineering.

For SDHA to work effectively, potential accidents as well as past accidents must be determined and analyzed. The analysis needs to be able to identify all the safety related risks. The overall goal is to identify these risk and eliminate or control them to an acceptable level. This task may seem simple on a smaller scale, but this is mostly done looking at a larger picture, or multicausal progression.

Hammer [6] talks about the different categories within SDHA and determining which hazards are responsible for accidents is a lot harder than it seems. Hazards are classified into initiating, contributory, and primary hazards.

$\mathrm{X}$ - Initiating Hazards: start of contrary sequence

$\mathrm{Y}$ - Contributory Hazards: dangerous acts or conditions

$\mathrm{Z}$ - Primary Hazards: possibility for harm

\section{Illustrative example}

Adverse event models are a useful tool to relate the concepts of system risks, accidents and scenarios. It helps to understand how complex the hazards can be and what effect they will have on the entire system. NASA could have used an adverse event model for the solid rocket booster field joint and predicted any defects associated with the mission. The analysis team could have done simulations of the mission; mocking the conditions of the rocket and stresses it would undergo, to predict any failures in the joint. Running the analysis threw multiple mock test flights would help to predict any failures associated with hardware reuse. Figure 2 below is an example of the adverse event model for the NASA Challenger Solid-Rocket Booster accident: 


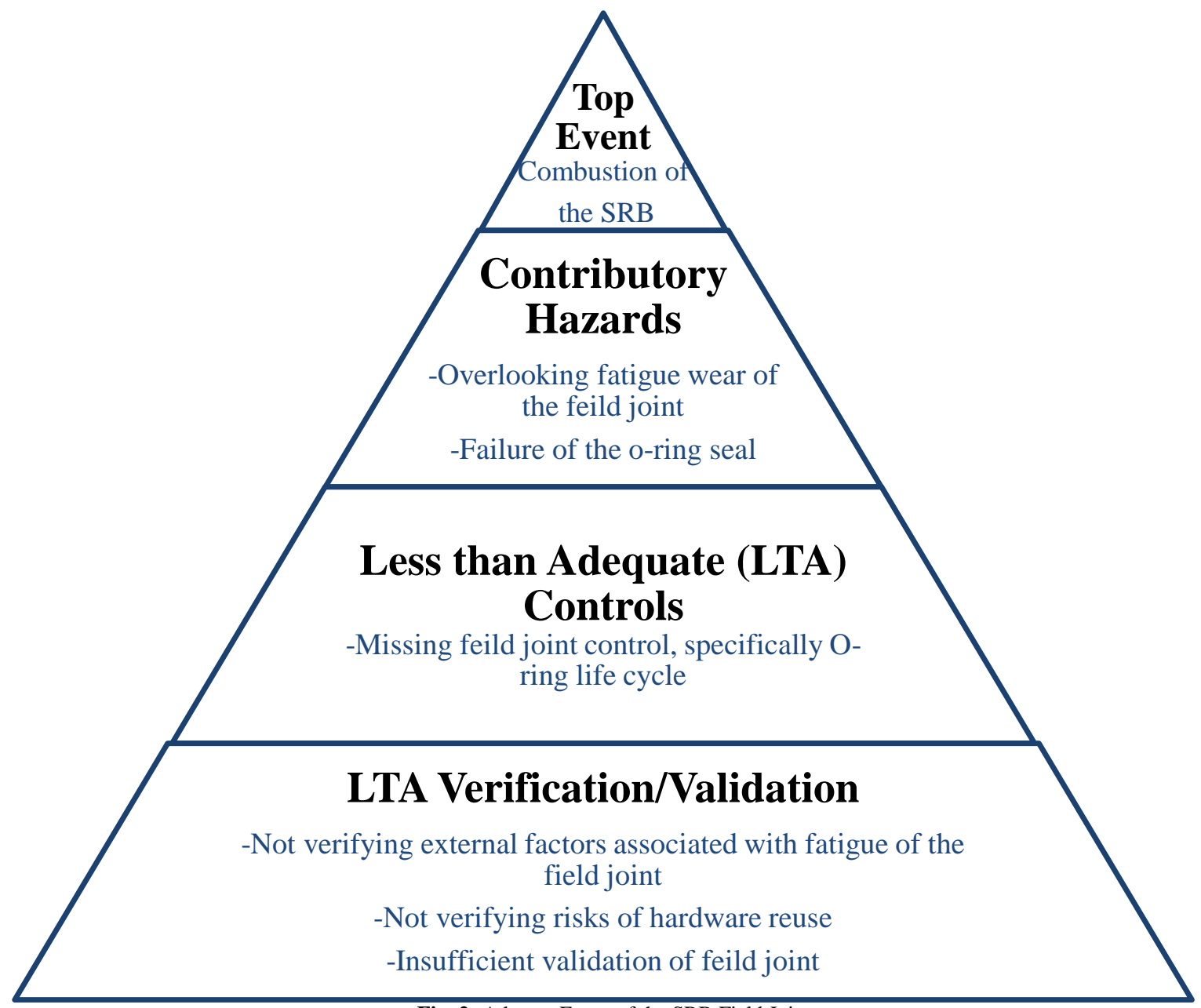

Fig. 2: Adverse Event of the SRB Field Joint.

Hazard and Operability Analysis (HAZOP) is another useful technique for identifying hazards within a system. It is also useful for identifying operability problems. When performing a HAZOP, it is important to notice foreseeable nonconformities or events that are undesirable with the system. This information is then used to perform a systematic study of the process. Calculating the criticality of failure effects would be useful in the development of the SRB. Criticality is a combination of severity and probability. The formula is as follows:

$$
\mathrm{Cr}=\mathrm{P} \times \mathrm{B} \times \mathrm{S}
$$

Where $\mathrm{P}=$ the probability of occurrence in a year, $\mathrm{B}=$ the conditional probability that the severest consequence will occur, and $\mathrm{S}$ $=$ severity of the severest consequence [9].

By combining the adverse effect model and HAZOP calculations, hazards and failures of the solid rocket booster field joint could have been predicted, assessed, and modified for a longer life cycle. Although these calculations and diagrams seems tedious and minute, high risk failures could have been suspected and avoided.

\section{Conclusion}

When complex systems are being developed, risk assessment is important to consider. It takes time and man power to facilitate, but the return on investment is infinite. Predicting all possible outcomes of a mission seems overwhelming, but with the proper approach and tools, it can be simplified and easily delegated properly across the team. Looking closely at the scenario-driven hazard analysis, the failure of the solid rocket booster field joint could have been avoided. There are many risk monitoring strategies that could have been utilized, such as adverse event models and HAZOP, to foresee the failure. When systems undergo stress and wear of their materials, proactive risk assessment should be completed. All departments within a system must work together and communicate their predictions for a risk assessment process to work. Thinking outside the box and simulating unfavorable conditions in a mission to push the limits of the system will ensure a safe, reliable product.

\section{References}

[1] Bos, Carole "Solid Rocket Booster - Exploded View" AwesomeStories.com. Retrieved from http://www.awesomestories.com/asset/view/Solid-Rocket-BoosterExploded-View on March 3, 2015.

[2] Dismukes, K. (2002, October 22). Space Shuttle Basics. Retrieved from National Aeronautics and Space Administration: Retrived from

http://spaceflight.nasa.gov/shuttle/reference/basics/srb/index.html on March 3, 2015.

[3] Dumoulin, J. (2015, February 25). NSTS 1988 Shuttle Reference Manual. Retrieved from National Aeronautics and Space Administration: Retrived from http://science.ksc.nasa.gov/shuttle/technology/stsnewsref/srb.html\#srb on March 3, 2015.

[4] Environmental Protection Agency. (2012, July 31). Risk Assessment. Retrieved from United States Environmrntal Protection Agency: Retrived from http://epa.gov/riskassessment/basicinformation.htm\#arisk on March $5,2015$.

[5] Harris, A. (2013, October 31). 6 Unexpected Ways Six Sigma Can Benefit Your Company. Retrieved from Process Excellence Network: http://www.processexcellencenetwork.com/lean-six-sigmabusiness-transformation/articles/6-ways-six-sigma-can-benefityour-company/ on March 2, 2015.

[6] Hammer, W. (1972). Handbook of System and Product Safety. Englewood Cliffs, NJ: Prentice-Hall.

[7] Hoover, K., \& Fowler, W. (23, February 2015). Spacecraft design archive. Retrieved from Texas Space Grant Consortium: Retrived 
from

http://www.tsgc.utexas.edu/archive/general/ethics/boosters.html on MArch 3, 2015.

[8] Ionita, M. T., America, P., Hammer, D. K., Obbink, H., \& Trienekens, J. J. (2004). A Scenario-Driven Approach for Value, Risk, and Cost Analysis in System Architecting for Innovation. In Software Architecture (pp. 277, 280). The Netherlands. http://dx.doi.org/10.1109/wicsa.2004.1310709.

[9] Jenab, K. (2015, March 15). Technical Risk Management. Daytona Beach, Florida, United States.

[10] Jenab K. \& Nicol T. (In Press). The Use of Perturbation with Monte Carlo Simulation Approach to Estimating the Reliability of the Space Shuttle Field Joints. International Journal for Computational Methods in Engineering Science \& Mechanics.

[11] Jenab K., Herrin J., \& Khoury S. (2015). System hazard platform: Case study NASA field joint failure. International Journal Mechanical Engineering Research, 5(2), 9-16. http://dx.doi.org/10.5539/mer.v5n2p9.

[12] Jenab K., Blecher R.M., \& Moslehpour S. (In Press). SRB field joints failure analysis using fuzzy FMEA. International Journal of $\begin{array}{llll}\text { Physics and } & \text { 3(1), }\end{array}$ http://dx.doi.org/10.15640/ijpa.v3n1a1.

[13] Jenab K. \& Moslehpour S. (2015). Failure analysis: Case study challenger SRB field joint. International Journal of Engineering and Technology. 8(6), In Press.

[14] Jenab K., Fine T., Khoury S., \& Moslehpour S. (2015). CauseConsequence analysis for NASA's space transportation system (STS) - solid rocket booster (SRB). International Journal of Business and Management. 10(8), 23-28. http://dx.doi.org/10.5539/ijbm.v10n8p23.

[15] Jenab K., Khoury S., \& Rodriguez S. (2015). Effective FMEA analysis or not? Strategic Management Quarterly. 3(2), 25-36. http://dx.doi.org/10.15640/smq.v3n2a2.

[16] Jenab K. \& Kelley T. K. (2015). Bayesian Failure Modes and Effects Analysis: Case Study for the 1986 Challenger Failure. International Journal of Engineering Research and Technology. 4(5), $685-$ 690.

[17] Jenab K. \& Pineau J. (2015). Failure Mode and Effect Analysis on Safety Critical Components of Space Travel. Management Science Letters. 5(7), 669-678. http://dx.doi.org/10.5267/j.msl.2015.5.006

[18] John F. Kennedy Space Center. (1994, September). Space Shuttle Solid Rocket Booster Retrieval Ships. Retrieved from NASA Facts Online: http://www-pao.ksc.nasa.gov/kscpao/nasafact/ships.htm.

[19] Leone, D. (2011, June 18). NASA's New Heavy-Lift Launcher Would First Fly With Solid Rocket Booster. Retrieved from Space.com: http://www.space.com/12006-nasa-heavy-lift-rocketdesign-includes-solid-boosters.html.

[20] Main, B. W. (2004). Risk assessment. Professional Safety, 49(12), 37-47. Retrieved from <http://search.proquest.com.ezproxy.libproxy.db.erau.edu/docview/ 200367853 ? accountid=27203> on March 3, 2015.

[21] NASA. (1986, June 6). The Presidential Commison on the Sapce Shuttle Challenger Accident Report. Retrieved from National Aeronautics and Space Administration: http://science.ksc.nasa.gov/shuttle/missions/51-1/docs/rogerscommission/Chapter-4.txt on March 3, 2015.

[22] Szondy, D. (2012, October 4). NASA building world's largest solidfuel rocket. Retrieved from Gizmag: http://www.gizmag.com/slslargest-solid-rocket/24408/ on March 3, 2015. 